\title{
A Psicologia no Rio Grande do Norte: caracterização geral da formação acadêmica e do exercício profissional
}

\author{
Oswaldo H. Yamamoto \\ Gilmara da S. Siqueira \\ Samantha C. da Costa Oliveira \\ Universidade Federal do Rio Grande do Norte
}

O objetivo do presente estudo foi empreender um mapeamento preliminar da situação da psicologia no estado, no sentido de atualizar informações gerais sobre as condições da profissão e do ensino de Psicologia no Rio Grande do Norte. Um questionário padronizado foi enviado por via postal a todos os profissionais inscritos no Conselho Regional de Psicologia, $2^{\mathrm{a}}$ Região, residentes no RN (um total de 448, em agosto de 1995), com uma amostra final de 190 psicólogos. Dentre os principais resultados - que confirmam dados nacionais (Conselho Federal de Psicologia, 1988) e locais (Yamamoto, 1988) - figuram o marcante predomínio da área da Psicologia da Saúde $(67,5 \%)$, seguida pela Psicologia do Trabalho (14,4\%), Educacional $(10,1 \%)$ e outras, em uma profissão essencialmente feminina $(88,4 \%)$. São sugeridas algumas linhas de interpretação dos dados, dentro dos limites permitidos por um mapeamento amplo, primeira etapa de um projeto inclusivo que visa um detalhamento do exercício profissional dos psicólogos do estado - enfatizando-se as atividades desenvolvidas nas diversas áreas associadas às condições da formação acadêmica.

Palavras-chave: Psicologia no Brasil, Psicologia no RN, Atuação profissional do psicólogo, Formação acadêmica do psicólogo. 
$\mathrm{E}$ m um trabalho que veio a público em 1975, Sylvia Leser de Mello empreendia um esforço pioneiro no sentido de captar as características da formação e da atuação profissional dos psicólogos no Estado de São Paulo. Vivíamos, então, uma conjuntura histórica marcada pelo vislumbre de transformações políticas em meio à luta contra a autocracia burguesa e pela democratização do país - com um progressivo engajamento dos intelectuais e uma intensiva politização de seus movimentos (Pécaut, 1990; Yamamoto, 1996a). No plano específico da psicologia, tínhamos uma profissão em busca de identidade, pouco menos de três lustros após seu reconhecimento, e uma formação acadêmica em franco processo de expansão quantitativa, na esteira das reformas de ensino que ensejaram a multiplicação de universidades e instituições de ensino superior no Brasil. Conquanto o universo com o qual Mello trabalhava fosse ainda tão reduzido - apenas 170 psicólogos! -, e suas ilações carregassem o peso das limitações por aquele impostas, a realidade é que suas categorias de análise e sua forma de condução da investigação acabaram por tornar-se modelo das reflexões dos profissionais da área.

Anos após, as entidades profissionais dos psicólogos - seja nos âmbitos estaduais, seja em âmbito nacional (Conselho Federal de Psicologia, 1988, 1992, 1994; Conselho Regional de Psicologia- 6 a Região, 1995; Sindicato dos Psicólogos no Estado de São Paulo \& Conselho Regional de Psicologia- $6^{a}$ Região, 1984) - ao lado de diversos estudiosos de forma isolada (entre os quais, Campos, 1983; Figueiredo, 1989; Japiassu, 1979; Patto, 1984; Yamamoto, 1987, 1988, 1996b; Yamamoto et al., 1990), promoveram diversas avaliações da profissão, procurando dar conta das novas realidades enfrentadas pelos psicólogos - tornando a profissão, certamente, uma das que mais explicitamente buscava se avaliar. O que instiga os psicólogos a conduzirem esses reiterados estudos acerca de sua própria profissão ainda é uma questão em aberto: insatisfação com os caminhos trilhados, imperativos éticos, a amplitude/indefinição da área - ou combinações destes e de outros fatores? ${ }^{1}$

As razões, todavia, não nos tocam aqui diretamente; o que é relevante assinalar é que os levantamentos empreendidos pareciam 
apontar para um quadro pouco animador: quanto ao exercício profissional, as condições de trabalho e de remuneração encontravam-se abaixo das expectativas, os índices de subemprego e desemprego em níveis assustadores, uma dispersão de atribuições que podem configurar mais a ausência de identidade que a riqueza de possibilidades da profissão, entre outros pontos; quanto à formação, uma equivalente desigualdade de condições proporcionadas pelos cursos como um dos sintomas da crise do modelo universitário implantado pelas reformas da transição da década de 60 (Conselho Federal de Psicologia, 1988).

A realidade da profissão, nacionalmente tomada, não mais tem sido alvo de avaliações após o extensivo projeto de pesquisa empreendido pelo Conselho Federal de Psicologia (1988). Ao longo dos anos que se seguiram àquele esforço, a tendência parece ser as iniciativas localizadas, com estudos circunscritos, temática ou geograficamente. E, nos últimos anos, alguns deles têm privilegiado a emergência de novos espaços de atuação que vêm se somar e/ou deslocar as áreas tradicionais (Conselho Federal de Psicologia, 1992, 1994). A importância disso é evidente: se a realidade da psicologia, cujo desenho vinha se delineando desde o pioneiro estudo de Mello (1975a), apontava, de um lado, para o esgotamento em termos do mercado de trabalho e, por outro, para a exigência cada vez crescente de uma ação socialmente mais significativa, contrapondo-se ao modelo tradicional de atuação clinicamente orientado, a emergência de novas formas de inserção profissional não poderia deixar de ser promissora.

Um levantamento preliminar realizado com a área escolar em Natal, no entanto, nos fornece indicações inquietantes (Yamamoto, Spinelli e Carvalho, 1996). Se, de fato, é possível e desejável falarmos em construção de novos espaços de atuação nos centros em que a psicologia já se consolidou enquanto uma profissão - e não nos importam, aqui, as suas mazelas -, em áreas geograficamente distantes do eixo sul-sudeste, a realidade parece ser bastante diversa. Em outras palavras, a psicologia ainda é uma atividade profissional em busca de um reconhecimento público e de consolidação no mercado de trabalho no Rio Grande do Nor- 
te, a julgar pelos dados preliminares e setoriais obtidos no estudo em questão. É exatamente nesse espaço que se situa este projeto.

Destarte, este estudo caminha na direção apontada - com relação à situação da psicologia no Rio Grande do Norte - à semelhança de outros empreendidos pelo Brasil. Em um estudo preliminar levado a efeito anos atrás (Yamamoto, 1988), foram delineados os contornos da atuação dos psicólogos locais. $\mathrm{Na}$ ocasião, eram 234 profissionais registrados junto ao Conselho Regional de Psicologia no estado, 197 dos quais na capital. O levantamento empreendido com uma parcela significativa daqueles profissionais $(\mathrm{N}=149)$ apontava que atuavam na área "clínica", 59,1\% do total; "organizacional", 13,4\%; "escolar", 8,1\%; outras, $0,7 \%$. A estes, agregavam-se $18,8 \%$ atuando fora do âmbito propriamente dito do campo profissional do psicólogo, seja exclusivamente na docência, seja em outros campos de atividade profissional. Em um estudo mais detido do segmento "psicologia escolar", o quadro descortinado apresentava-se bastante próximo àquele referido anteriormente (Yamamoto et al., 1990) .

Decorridos pouco menos de dez anos, uma tal caracterização apresenta evidentes sinais de anacronismo, seja simplesmente pelo próprio evolver do quadro da psicologia local, seja porque a conceptualização mesma dos campos de atuação exigem atualização (Bastos, 1988; Carvalho, 1988; Conselho Federal de Psicologia, 1992), dada a diferenciação teórico-profissional experimentada nesses anos. Em termos do enquadramento mais amplo dos estudos sobre a profissão, a intensa - e por vezes, superficial - politização dos movimentos acadêmico-profissionais, rebatimento do envolvimento político dos intelectuais no embate pela democratização, não mais existe hoje. As avaliações profissionais caminham, tendencialmente, na direção do cumprimento de exigências acadêmicas mais rigorosas. Eé importante que assim seja: um compromisso mais estrito com a qualidade teórica da produção, sem perder de vista as dimensões políticas e éticas da atividade profissional.

A partir de um levantamento setorizado - para a área escolar - hipotetizamos que algumas inflexões significativas ocorreram na 
configuração da psicologia no estado. De um quadro semelhante aos "primeiros passos" esboçados, reproduzindo aquele esboçado por Mello no trabalho de 1975 em São Paulo, com um retardo de três lustros, o estudo preliminar recentemente conduzido (Yamamoto et al., 1996) parece nos indicar que a psicologia local evolveu na direção do quadro nacional descrito na coletânea do Conselho Federal de Psicologia, de 1988. As novas modalidades e os espaços emergentes detectados nos últimos estudos do Conselho Federal de Psicologia (1992, 1994), contudo, não parecem encontrar eco aqui, ao menos na área enfocada.

O presente estudo constitui-se na primeira parte de um projeto mais amplo, que pretende dar continuidade a esta linha de investigação histórica, procurando abordar especificamente alguns aspectos da prática profissional dos psicólogos, em âmbito estadual. Nesse sentido, os resultados aqui apresentados dizem respeito à etapa de mapeamento dos profissionais inscritos no Conselho Regional de Psicologia, residentes no Estado do Rio Grande do Norte, visando uma caracterização geral e ampla de aspectos das trajetórias acadêmica e profissionais, assim como de elementos que nos permitam configurar as condições atuais do seu exercício profissional.

Além de atualizar dados, certamente já defasados desde o último estudo, intentamos caminhar na direção de um entendimento mais acurado da realidade da psicologia potiguar: uma caracterização mais completa e precisa, buscando detectar os sinais de movimento subjacentes à prática profissional - além de discutir as condições teórico-instrumentais da prática e as perspectivas que se lhes apresentavam. Ao lado da prática profissional, buscamos caracterizar as formas e as condições para a formação acadêmica do psicólogo em atuação no Estado, visando colocar à disposição dos profissionais e da universidade, uma caracterização profissional que permitisse tanto um conhecimento acerca da realidade natalense, tão precisa quanto possível, como uma condição para uma atuação mais compatível com a realidade estadual, quanto eventuais correções de rota, na prática e na formação. 


\section{O estudo: elementos do método}

Uma listagem dos psicólogos residentes no território norterio-grandense, inscritos na Segunda Região Administrativa do Conselho Federal de Psicologia, sediada em Recife (PE) ${ }^{2}$, que comportava em agosto de 1995, o total de 448 profissionais, serviu de base para a definição da população-alvo deste estudo.

O instrumento - um questionário com 14 quesitos distribuídos em três seções (Dados Gerais, Formação Acadêmica e Exercício Profissional), com uma estruturação que permitisse abreviar o tempo de preenchimento -, foi enviado por via postal para todos os profissionais arrolados na listagem acima referida.

Os dados deste estudo dizem respeito a um total de 190 profissionais $(42,4 \%)$ que retornaram questionários válidos. Os demais agrupam-se em três categorias: devolução além do prazo estabelecido, retorno da correspondência por problemas no endereço do destinatário, e ausência de resposta. Desta forma, os resultados a que faremos alusão aqui devem ser tomados levando-se em consideração que o seu desenho não previu um plano de amostragem, uma vez que a lógica que presidiu o planejamento da pesquisa foi censitária.

\section{Caracterização geral dos psicólogos do Rio Grande do Norte}

Uma das características notáveis que têm chamado a atenção dos estudiosos da profissão de psicólogo é o enorme predomínio do sexo feminino sobre o masculino (Rosemberg, 1984; Rosas, Rosas e Xavier, 1988), largamente concebida como uma profissão essencialmente feminina. Destarte, a literatura registra um percentual de mulheres psicólogas na ordem de 87,6\% no Estado de São Paulo (Sindicato dos Psicólogos no Estado de São Paulo \& Conselho Regional de Psicologia- $6{ }^{\text {a }}$ Região, 1984), de 86,6\% em nível nacional (Rosas et al., 1988) e de 89,2\% na Sexta Região Administrativa (SP, MT e MS) (Conselho Regional de Psicologia- 6 a Região, 1995). Se tomarmos os dados locais setorizados (referentes à área escolar), observaremos um total de $81 \%$ 
(Yamamoto et al., 1990). Confrontados com os dados históricos, o primeiro levantamento realizado por Mello (1975a) já delineava a tendência: $82,9 \%$ daqueles profissionais paulistanos diplomados até o ano de 1970 era do sexo feminino. Dessa forma, os 88,4\% registrados para o sexo feminino neste estudo pouco diferem dos dados já arrolados.

\begin{tabular}{|c|c|c|}
\hline $\begin{array}{l}\text { Tabela } 1 \\
\text { Dados gerais dos psicólogos }\end{array}$ & $\mathrm{n}$ & $\%$ \\
\hline A. Sexo & 190 & 100,0 \\
\hline Feminino & 168 & 88,4 \\
\hline Masculino & 22 & 11,6 \\
\hline B. Faixa etária (em anos) & $189^{*}$ & 100,0 \\
\hline até 25 & 11 & 5,8 \\
\hline $26-30$ & 50 & 26,3 \\
\hline $31-35$ & 48 & 25,3 \\
\hline $36-40$ & 34 & 17,9 \\
\hline $41-45$ & 32 & 16,8 \\
\hline $46-50$ & 9 & 4,7 \\
\hline acima de 50 & 5 & 2,6 \\
\hline C. Estado civil & $188^{*}$ & 100,0 \\
\hline Solteiro & 67 & 35,3 \\
\hline Casado & 99 & 52,1 \\
\hline Outros & 22 & 11,6 \\
\hline D. Naturalidade (UF) & 190 & 100,0 \\
\hline Rio Grande do Norte & 130 & 68,4 \\
\hline Outros & 60 & 31,6 \\
\hline E. Naturalidade (município) & 190 & 100,0 \\
\hline Natal (RN) & 80 & 42,1 \\
\hline Outros & 110 & 57,9 \\
\hline F. Local de residência (município) & 190 & 100,0 \\
\hline Natal & 176 & 92,6 \\
\hline Caicó & 4 & 2,1 \\
\hline Parnamirim & 3 & 1,6 \\
\hline Mossoró & 2 & 1,1 \\
\hline Outros (5 municípios) & 5 & 2,6 \\
\hline
\end{tabular}


Rosemberg (1984) aponta três hipóteses tentativas para explicar esse predomínio feminino: o processo de socialização vertical reforçando os modelos sexuais tradicionais; a segregação ocupacional e os benefícios para aquelas que necessitam enfrentar o que denomina de "dupla perspectiva de vida" (i.e., profissional e doméstica).

Não há elementos para discutir, no âmbito deste estudo, as determinações específicas da distribuição aqui verificada. Contudo, é conveniente agregar algumas questões à discussão já acumulada.

Parece-nos que há, no que tange à procura pelo curso de Psicologia, um elemento adicional aos que têm sido discutidos nos estudos. De início, conforme lembra Rosemberg (1984, p.7), há que se ressaltar a própria expansão feminina nos cursos superiores tomados globalmente - ainda que, em termos absolutos, a presença masculina ainda seja maior. No caso específico da Universidade Federal do Rio Grande do Norte, apenas para exemplificar, dentre os alunos cadastrados no segundo semestre de 1994, o percentual de estudantes do sexo feminino era de 44,6\% (6152), contra 55,4\% (7653) do sexo masculino. Contudo, no campo específico das Humanidades, o quadro se inverte, com o predomínio feminino expresso nos 52,4\% (1791) contra 47,6\% (1629). No curso de Psicologia, nesse mesmo período, estavam cadastrados 338 estudantes, sendo 244 (72,2\%) mulheres e $94(27,8 \%)$ homens $^{3}$.

O que esse dado, apenas ilustrativo, nos sinaliza, é que os estudos têm apontado a "natureza feminina" da profissão, mas têm deixado de lado o crescimento pela procura especificamente para o curso de Psicologia dentre as chamadas "profissões femininas". Talvez o estereótipo de que as profissões femininas são pior remuneradas, "compensadas" pelo seu valor social - o sacerdócio que acompanha a "missão" do professor, por exemplo - possa ser explicação tentadora. Ainda mais, se considerarmos, com Carvalho et al. (1988), que, dentre os valores implícitos para a escolha da profissão, a mais relevante seja a característica de ser "voltada para o outro". Sem embargo, há um traço que distingue a Psicologia dos demais cursos/profissões do campo das hu- 
manidades: ela é a única que confere ao profissional um estatuto de "profissional liberal". Em outras palavras, o modelo profissional do psicólogo forjado pelos cursos - conquanto em termos da natureza do conhecimento situe-se mais propriamente dentro das chamadas ciências sociais -, é mais assemelhado àqueles do campo da saúde. Mais do que isso, na realidade, a própria estrutura do curso de Psicologia, ainda que carregue elementos de uma formação em humanidades, é mais próxima dos cursos da área da saúde - a Medicina como parâmetro. Talvez essa característica de profissionalização nesse nível - seja um dos fatores relacionados a uma migração dos cursos/profissões tradicionalmente femininos, vinculadas ao magistério, para a Psicologia.

Além do caráter feminino do curso e da profissão, Rosas et al. (1988) também destacam a juventude dos profissionais. De fato, os nossos dados apontam que os psicólogos norte-riograndenses também são relativamente jovens, com 75,3\% dos mesmos na faixa de até 40 anos. Também neste aspecto, o estudo replica dados recentes relatados na literatura: 76,3\% dos psicólogos na Sexta Região Administrativa têm menos de 40 anos (Conselho Regional de Psicologia- $6{ }^{\mathrm{a}}$ Região, 1995). Se contrastado com os dados nacionais de 1988 - os quais induziam a observação de Rosas et al. (1988, p.43) sobre a juventude da profissão-, estes últimos sugerem um processo de "rejuvenecimento", pois, na época, 46,3\% tinham menos de 39 anos. No caso específico do Rio Grande do Norte, talvez as explicações residam em dois fatores: no escoamento, nos primeiros anos de funcionamento do curso, do contingente represado, isto é, de vestibulandos atípicos no que tange à idade, e na diminuição da proporção de profissionais oriundos de outros centros, que marcaram o início da psicologia local, pela formação sucessiva de psicólogos pela UFRN. Com o passar dos anos, e com a consolidação do curso, contingentes de vestibulandos recém-saídos do ensino secundário passaram a ocupar as vagas do curso de Psicologia da UFRN, promovendo o rebaixamento da faixa etária do próprio profissional. 
Com relação ao estado civil, os dados obtidos $(52,1 \%$ de casados; $35,3 \%$ de solteiros e $11,6 \%$ em outras situações) também não diferem dos dados nacionais $(53,7 \% ; 31,1 \%$ e $14,2 \%)$ (Rosas et al., 1988) e regionais (51,6\%\%; 37,8\% e 10,6\%) (Conselho Regional de Psicologia- $6^{\mathrm{a}}$ Região, 1995).

Tomados isoladamente, estes conjuntos de dados talvez não tenham significado maior. Todavia, não nos parece desarrazoado supor que algumas das características da própria prática profissional e das condições do seu exercício talvez estejam relacionadas à conjunção desses três vetores.

Para registro apenas: como seria previsível, em um estado com apenas um curso de formação, a maioria dos profissionais é natural do $\mathrm{RN}(68,1 \%), 42,1 \%$ dos quais, natalenses. Contudo, o dado relevante, já relatado por Rosas et al. (1988), é a enorme concentração de profissionais na capital. O dado nacional apresentado nesse estudo apontava $69 \%$ dos profissionais atuando nas capitais e, especificamente no Rio Grande do Norte, $93 \%$. Esse dado não se altera de forma significativa no presente estudo: considerando-se o total dos psicólogos que responderam ao questionário, 92,6\% estavam na capital, com apenas 8 dos demais 150 municípios instalados no estado contando com o concurso permanente de profissionais de Psicologia. Se considerarmos as listagens fornecidas pelo Conselho Regional de Psicologia, $2^{\mathrm{a}}$ Região (dados de 1994 e 1995), existiriam tão somente 14 municípios com psicólogos residentes, incluindo a capital.

\section{A formação acadêmica dos psicólogos}

É exatamente o fato de ser a Universidade Federal do Rio Grande do Norte (UFRN) a única agência formadora de psicólogos no estado a primeira característica notável dos dados acerca dos profissionais. De fato, a UFRN é responsável pela formação básica de 77,4\% dos psicólogos registrados no estado. Trata-se de um elemento fundamental na análise: de um lado, seguramente, muito das eventuais virtudes e deficiências - características, enfim - do exercício profissional, podem ser buscadas na conformação do Curso de Psicologia da UFRN; por outro, não 
deixa de ser inquietante que uma única agência seja a virtual responsável pelo perfil profissional da categoria no estado.

O estudo do Conselho Regional de Psicologia- $6{ }^{\text {a }}$ Região (1995, p. 13) aponta um total de 107 cursos de psicologia no Brasil, no ano de 1993. Somente naquela região (SP, MS e MT), localizavam-se mais de $36 \%$ desses cursos. Na região Nordeste, por seu turno, o levantamento de 1988 do Conselho Federal de Psicologia (Gomide, 1988, p.70) apontava 14 cursos, ou seja, pouco mais de $17 \%$ do total levantado então.

\begin{tabular}{lrr}
\hline Tabela 2 & & \\
Formação acadêmica & $\mathrm{n}$ & $\%$ \\
\hline A. Agência formadora & 190 & 100,0 \\
UFRN & 43 & 77,4 \\
Outra & $189^{*}$ & 100,0 \\
B. Área de estágio curricular obrigatório & 126 & 66,7 \\
Clínica & 23 & 12,2 \\
Organizacional & 13 & 6,9 \\
Escolar & 8 & 4,2 \\
Hospitalar & 4 & 4,2 \\
Social e Comunitária & 1 & 0,5 \\
Outras & 14 & 7,4 \\
Mais de uma área & $246^{* *}$ & 100,0 \\
C. Estudos complementares & 62 & 25,2 \\
Formação clínica & 79 & 32,1 \\
Especialização & 19 & 7,7 \\
Mestrado & 1 & 0,4 \\
Doutorado & 42 & 17,1 \\
Outras modalidades & 43 & 17,5 \\
Nenhum & & \\
*Diferenças de $n$ devidas a respostas prejudicadas. & \multicolumn{3}{l}{} \\
** Respostas múltiplas admitidas. & &
\end{tabular}

A situação do Rio Grande do Norte, no contexto da distribuição regional, não é, portanto, atípica. Contudo, é importante assinalar as implicações de uma tal concentração de responsabilidades na formação de uma determinada categoria de profis- 
sionais. Se, por um lado, uma diversidade de agência traz consigo o risco de padrões de ensino díspares do ponto de vista qualitativo, por outro, permite uma diluição das influências, se tomada a configuração geral, com relação à situação de fonte única.

O curso de Psicologia da UFRN está estruturado de forma que o estágio curricular obrigatório seja objeto de opção do aluno por apenas uma área ${ }^{5}$. Os dados demonstram que a opção pela área clínica é bastante significativa: duas terças partes dos alunos escolhem estagiar nela. Na seqüência, as áreas organizacional e escolar, e outras de menor procura.

Com relação a estes dados, nenhuma surpresa: eles, na realidade, antecipam a opção profissional, que será massacrantemente clínica, fato que levou Mello (1975a) a afirmar que o curso de Psicologia não forma psicólogos clínicos, mas transforma psicólogos em clínicos.

Um dado, contudo, merece destaque: a presença, como quarta opção, pela área "Hospitalar". Pela adoção da nomenclatura proposta no estudo do Conselho Regional de Psicologia- $6{ }^{\mathrm{a}} \mathrm{Re}-$ gião (1995), de Psicologia da Saúde, para todo o conjunto que abarca tanto a atividade especificamente clínica, quanto as novas modalidades de ação que vêm surgindo - como é o caso da "Psicologia Hospitalar" -, os dados sobre atuação que se verá a seguir no presente estudo, foram apresentados de forma agregada. Contudo, esta sub-área constitui-se em uma opção presente tanto enquanto campo de estágio, quanto de pós-graduação - fato que deve ser registrado para posterior discussão.

Aqui, novamente, temos uma consequiência do fato de a UFRN ser a única instituição a formar psicólogos no estado: mudanças na configuração da formação e interesses dos docentes daquela universidade introduzem alterações perceptíveis no delineamento de todo o campo de atuação do profissional local.

Observe-se, ainda, com relação à formação, que a busca de complementação após os estudos de graduação é uma preocupação central, presente em $82,5 \%$ dos profissionais. Por outro lado, é interessante notar que as modalidades de estudos pós- 
graduados stricto sensu são preteridos com relação ao lato sensu e à chamada formação clínica, com cursos e/ou supervisão de profissionais mais experientes e, muitas vezes, implicando um deslocamento para outras capitais.

\section{O exercício profissional}

Uma análise da situação do mercado de trabalho, no caso específico da Psicologia, requer, conforme lembra Bastos (1990, p.29), a consideração de uma terceira dimensão, além das tradicionais - quantidade de emprego e remuneração: a modalidade do trabalho que é prestada pelo psicólogo, dada a diversidade da atuação desse profissional.

\begin{tabular}{|c|c|c|}
\hline Tabela 3 & & \\
\hline Condições do exercício profissional & $\mathrm{n}$ & $\%$ \\
\hline A. Situação atual & 190 & 100,0 \\
\hline Trabalha em psicologia & 163 & 85,8 \\
\hline Fora da psicologia & 27 & 14,2 \\
\hline B. Número de atividades (em Psicologia) & $163^{*}$ & 100,0 \\
\hline Uma & 84 & 51,2 \\
\hline Mais de uma & 79 & 48,8 \\
\hline C. Faixa de renda em S. M. (em Psicologia) & $160^{* *}$ & 100,0 \\
\hline 1 a 2 & 19 & 11.9 \\
\hline 3 a 4 & 32 & 20,0 \\
\hline 5 a 6 & 25 & 15,6 \\
\hline 7 a 8 & 14 & 8,7 \\
\hline 9 a 10 & 12 & 7,5 \\
\hline 11 a 12 & 12 & 7,5 \\
\hline 13 a 14 & 9 & 5,6 \\
\hline 15 ou mais & 34 & 21,3 \\
\hline nenhuma & 3 & 1,9 \\
\hline
\end{tabular}

Para efeito deste estudo, distinguiremos os dois conjuntos: as condições gerais do exercício profissional e aquelas especificamente vinculadas à natureza do trabalho do psicólogo. Uma ob- 
servação liminar no que tange aos dados sobre a atividade: a despeito da solicitação de que se destacasse a sua atividade principal, para consideração em separado com relação às demais atividades, em alguns dos protocolos preenchidos isso não foi feito, com a alegação de que não haveria uma atividade principal. Como, pela natureza da coleta, não foi possível contemplar um detalhamento dessa questão no instrumento, à alternativa de perder os dados, decidiu-se assumir o risco de uma relativa imprecisão com relação à análise.

O primeiro aspecto que chama a atenção nesses dados é o expressivo percentual de psicólogos exercendo sua profissão: 85,8\%. A interpretação dessa informação, todavia, deve considerar algumas questões. De início, o fato de estarmos lidando com pouco menos da metade dos profissionais inscritos, já mencionado anteriormente. Mesmo supondo que os nossos 42,4\% representem a tendência do conjunto dos profissionais, existe um segundo elemento decisivo, se nossa análise recair sobre os diplomados do curso de Psicologia: estamos lidando com um contingente de profissionais que efetivamente encontra-se em condições de competir no mercado de trabalho através do seu registro junto ao Conselho Regional. Conforme a análise de Rosas et al. (1988, p.35), se tomarmos como base 1982-83, apenas $48 \%$ dos 13.736 diplomados regulariza sua situação junto aos conselhos de Psicologia!

De fato, levando-se em consideração que o total de psicólogos com situação regularizada junto aos conselhos é de 86.313 (Conselho Regional de Psicologia- $6^{\text {a }}$ Região, 1995, p. 32), e que os cursos de Psicologia no Brasil saltaram de 81 na época do estudo de Rosas et al. para 107, não nos parece desarrazoado supor que o contingente de egressos dos cursos de psicologia fora da profissão constitui a maioria. Se somarmos este contingente - ainda a ser levantado - com aqueles que, malgrado a sua regularização junto aos órgãos competentes, encontra-se fora do mercado de trabalho da Psicologia, o quadro do exercício profissional do psicólogo parece ser bastante desalentador.

As disquisições acima apenas colocam, na realidade, um conjunto de variáveis que merecem consideração na abordagem da 
questão em tela. Rigorosamente falando, o quadro tal qual ele se nos apresenta no Rio Grande do Norte parece promissor, conquanto seja necessário verificar as condições específicas de trabalho do psicólogo: o subemprego, a multiplicidade de atividades, entre outras.

Desta forma, 48,8\% dos que trabalham como psicólogos exercem outra atividade remunerada em Psicologia ${ }^{6}$. Analisados em conjunção com os dados referentes à remuneração (49,5\% concentrados entre 1 a 6 salários mínimos - S. M.), é forçoso reconhecer que as condições do exercício profissional não são tão estimulantes como a oferta de empregos fazia supor. De fato, a maior parte dos psicólogos do estado situa-se dentro dos $92,5 \%$ da população economicamente ativa do estado que percebe até 5 S. M. (Instituto Brasileiro de Geografia e Estatística [IBGE], s.d.). Os $34,4 \%$ dos profissionais de psicologia com rendimentos acima de $10 \mathrm{~S}$. M., portanto, fazem parte da seleta parcela da população norte-rio-grandense que se situa nessa faixa: apenas 3,1\%! Comparativamente, no estudo da Sexta Região Administrativa (Conselho Regional de Psicologia- $6{ }^{a}$ Região, 1995), os dados não são destoantes: a maior frequiência também se encontra na faixa de até $5 \mathrm{~S}$. M., conquanto que, em termos percentuais, haja um contingente menor de psicólogos (31\%). Se estendermos a faixa até 10 S. M., teríamos no estudo da Sexta Região, $59 \%$ dos profissionais, contra $63,7 \%$ no nosso levantamento, discrepância que pode ser facilmente tributada às diferenças das atividades econômicas e dos níveis de vida e de renda nas regiões nordeste e sudeste.

$\mathrm{O}$ último conjunto de dados diz respeito às características distintivas da atuação do psicólogo: as áreas e os correspondentes locais de vinculação profissional (Figura 1).

Utilizando as categorias sugeridas pelo estudo do Conselho

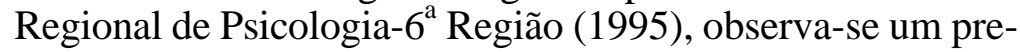
domínio bastante acentuado da área da Saúde $(67,6 \%$ ), com relação às demais (Trabalho, 14,4\%; Educacional, 10,1\% e Social, $2,1 \%)$.

Com relação a esses dados, é necessário reiterar que a classificação empregada é algo diferente da tradicionalmente reportada em estudos sobre a atuação psicológica. Além da já aludida 
Figura 1

Distribuição dos psicólogos norte-rio-grandenses

pelas áreas de atuação

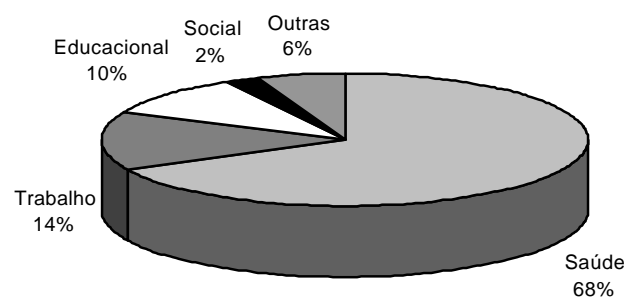

área da Saúde, que compreenderia tanto o conjunto de atividades exercidas na clínica, quanto aquelas desenvolvidas em instituições hospitalares e nos diversos equipamentos do campo da saúde pública, a nomenclatura Trabalho, Educacional e Social (englobando também as atividades usualmente conhecidas com a ambígua denominação de "comunitária"), são adotadas pela sua maior abrangência e poder descritivo.

Se os dados sugerem, à primeira vista, que há um movimento tendencial da Psicologia norte-rio-grandense em direção à área sanitária, esta ilação é apenas parcialmente verdadeira. De fato, se desagregarmos os dados referentes à área da Saúde, verificaremos que a modalidade tradicional clínica é largamente predominante: $61,7 \%$ dos profissionais dedica-se a tal atividade. Se observamos os dados referentes ao local de trabalho, o quadro desenha-se de maneira mais clara: o consultório particular continua com a preferência dos profissionais, com cerca de uma terça parte do total - ou, 48,8\% daqueles que atuam na área da Saúde.

Ainda com relação à vinculação profissional, é interessante observar que um considerável contingente de atividades são realizadas no setor público: 46\% exclusivamente, e 59,5\% no total, computados aqueles que exercem atividades nos dois setores. Estes dados que, por um lado, podem refletir uma tendência de 
absorção de contingentes ponderáveis de trabalhadores pelo setor público no estado, podem, por outro, indicar uma possibilidade aberta aos profissionais de psicologia para uma atuação mais substantiva no setor de prestação pública de serviços para setores da população sem acesso direto ao atendimento privado.

\begin{tabular}{lrr}
\hline Tabela 4 & & \\
Características do local de atuação & $\mathrm{n}$ & $\%$ \\
\hline A. Local de atuação & $183^{*}$ & 100,0 \\
Clínica psicológica & 72 & 39,4 \\
Secretarias da Saúde (Estado e Município) & 34 & 18,6 \\
Empresas & 23 & 12,6 \\
Instituições educacionais & 16 & 8,7 \\
Hospitais & 14 & 7,5 \\
Instituições-pessoas portadoras de deficiências & 14 & 7,5 \\
Outros & 10 & 5,7 \\
B. Natureza jurídica da instituição & 163 & 100,0 \\
Pública & 75 & 46,0 \\
Privada & 66 & 40,5 \\
Ambas & 22 & 13,5 \\
\hline${ }^{*}$ Respostas múltiplas admitidas. & \multicolumn{3}{c}{}
\end{tabular}

Retornando ao conjunto anterior, os locais, de uma certa forma, corroboram essa afirmação: há um percentual considerável de profissionais atuando nas secretarias de saúde, em hospitais, em escolas. Uma análise detalhada dos protocolos nos fornece dados importantes: são diversas unidades de saúde (municipais e estaduais) atendidas por psicólogos, além de serviços - estatais como o CRI (Centro de Reabilitação Infantil), o NAPS (Núcleo de Atenção Psicossocial), o SEPA (Serviço de Psicologia Aplicada, da UFRN), e diversos hospitais (incluindo-se o Hospital Universitário) - todos na área da Saúde. Na área Educacional, escolas públicas como a Escola Técnica Federal do Rio Grande do Norte e o Centro Estadual de Educação Especial já contam com psicólogos. Na área do Trabalho, diversos organismos municipais e estaduais contam com o concurso de psicólogos: CAERN (Companhia de Águas e Esgotos do RN), COSERN 
(Companhia Energética do RN), TELERN (Telecomunicações do RN), DETRAN (Departamento Estadual de Trânsito), ECT (Empresa Brasileira de Correios e Telégrafos), entre outros. E, algumas surpresas agradáveis: o ITEP (Instituto Técnico e Científico da Polícia), Delegacia de Defesa da Mulher e a Vara da Infância e da Juventude - prenunciando a abertura do campo Forense -, assim como o Centro Integrado de Atenção ao Idoso e o Serviço de Vigilância Sanitária também já contam com os préstimos profissionais de psicólogos.

Duas conclusões parecem emergir desses dados desagregados: de fato, há vislumbres de trabalhos em áreas novas, como o campo Hospitalar e mesmo o Forense-Judiciário; mas, mais importante, mesmo nas áreas tradicionais, a profissão de psicólogo no Estado parece dar sinais de estar atingindo uma capilaridade que indica um reconhecimento (social) da necessidade de seus serviços.

Apenas para visualizar, comparativamente, a distribuição geral das grandes áreas de atuação com os dados referidos na literatura (Conselho Federal de Psicologia, 1988; Conselho Regional de Psicologia- $6{ }^{\text {a }}$ Região, 1995; Mello, 1975a; Sindicato dos Psicólogos no Estado de São Paulo \& Conselho Regional de Psicologia- $6{ }^{\mathrm{a}}$ Região, 1984; Yamamoto, 1988), apresentamos a Figura 2.

Observe-se que as distribuições gerais das áreas são bastante próximas, com apenas uma inversão com relação à segunda área na preferência dos psicólogos do Conselho Regional de Psicologia- $6{ }^{\mathrm{a}}$ Região (1995). No mais, a maioria absoluta dos profissionais está engajada em atividades na área da saúde, seguido pela área do trabalho e, em terceiro, pela área educacional. Notese que os dados dos estudos de Mello (1975a), Sindicato dos Psicólogos no Estado de São Paulo \& Conselho Regional de Psicologia-6 ${ }^{\mathrm{a}}$ Região (1984), Yamamoto (1988) e Conselho Federal de Psicologia (1988) utilizam a classificação tradicional Clínica/Escolar/Organizacional (Trabalho ou Industrial) - e que somente foram comparados os dados referentes às três grandes $\mathrm{e}$ tradicionais áreas da psicologia. 
Figura 2

Distribuição dos psicólogos pelas áreas de atuação nos diversos estudos

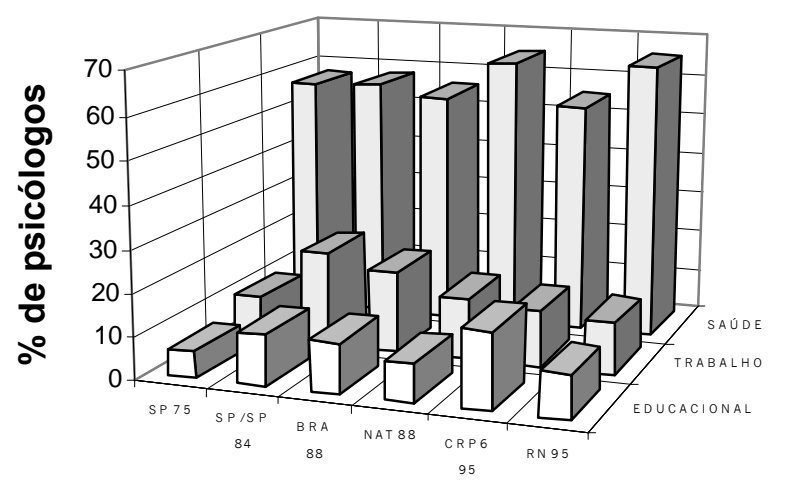

Áreas

\section{Estudos}

Uma vez que as áreas de abrangência dos estudos diferem, não é possível fazer qualquer inferência acerca de tendências no tempo.

Algumas reflexões sobre o mapeamento da psicologia potiguar

Sendo etapa de um projeto abrangente, com o intuito de um mapeamento amplo, os resultados deste estudo não permitem ir muito além no que tange às determinações que estão na base da configuração delineada. Contudo, algumas considerações se impõem.

A literatura arrolada aponta uma importante tendência da psicologia brasileira nos últimos anos: a tentativa de, saindo dos modelos tradicionais de ação, buscar novos espaços e modalidades de ação. Conquanto não implique que tais diretrizes novas apontem para caminhos socialmente mais significativos que os que vem sendo trilhados, é fato inconteste que o movimento da profissão abre perspectivas estimulantes. 
Tanto os dados apresentados aqui, quanto os do estudo referido alhures (Yamamoto et al., 1996), permitem apenas vislumbrar tênues perspectivas de mudança na psicologia potiguar. É bem verdade que, tomando-se os dados disponíveis na literatura, regionais e nacionais, também ela se afigura apenas tendencialmente (Yamamoto, 1996b).

De qualquer forma, a presença da sub-área Psicologia Hospitalar dentre os campos de atuação dos profissionais, como a quarta opção, não deixa de ser digna de registro. Se analisarmoso rol de disciplinas e as atividades desenvolvidas pelo Departamento de Psicologia da UFRN, encontraremos algumas surpresas interessantes: uma delas, enquanto uma área emergente - ainda que não se constitua em campo de estágio, no momento - de ensino de graduação e pós-graduação, de pesquisa e de extensão, é a Psicologia Ambiental. Da mesma forma, estudos sobre as temáticas do menor e da morte são desenvolvimentos novos que devem ser observados com atenção.

A constatação da vinculação profissional de psicólogos nos serviços públicos com um espectro tão amplo quanto a Delegacia de Defesa da Mulher, a Vigilância Sanitária ou os centros de atenção aos idosos, não deixa de ser alvissareira, em um estado com um contingente bastante reduzido de profissionais, e ainda em fase de consolidação.

É importante reiterar que a busca de novas alternativas - seja motivada por imposições de mercado, seja por avaliações internas indicando a necessidade de mudanças -, exige, por outro lado, o correspondente desenvolvimento de novos suportes teóricometodológicos - implicando alterações substantivas na formação do psicólogo. Considerando-se que se trata de uma formação que ainda não conseguiu equacionar os crônicos problemas relativos à preparação do profissional nos moldes "tradicionais", certamente há uma tarefa árdua pela frente ao propor inovações substantivas em seus rumos?

Seja qual for o evolver da psicologia - movimentação na direção de uma prestação pública de serviços auma parcela mais significativa da população brasileira ou permanência nas posturas e práticas tradicionalmente definidas - esta necessita ser colocada em contexto. Neste caso, isto nos remete a considerações de duas ordens. A 
primeira delas diz respeito aos constrangimentos na base material da sociedade que impõem limites e definem características da inserção profissional dos trabalhadores - consideradas as suas especificidades -, relacionados ao seu locus na divisão social e técnica do trabalho. Enquanto categoria profissional, os graus de liberdade não são, como é de uso corrente imaginar, tão largos, a ponto de permitir uma movimentação e/ou redirecionamento livres de perturbações (para este debate, ver entre outros, Campos, 1983 e Yamamoto, 1987 e Yamamoto et al., 1990). Contemporaneamente, levar em conta o contexto significa que, qualquer perspectiva que se delineie para a psicologia enquanto profissão deve passar pela discussão acerca das novas formas de sociabilidade postas pelas mudanças no mundo capitalista - em especial, por considerações acerca da restruturação produtiva sob o primado da globalização da economia e sua incidência nas práticas sociais, e do impacto da agenda neoliberal sobre a área do bem-estar (Antunes, 1995; Frigotto, 1995; Sader \& Gentili, 1995; Yamamoto, 1996b). Por outro lado, não se deve negar o papel dos atores sociais - os sujeitos da história -, na consideração do contexto. As determinações materiais não impõem configurações necessárias e imutáveis, dadas a priori - e o reconhecimento dos espaços de autonomia, ainda que relativa, é conseqüência da consideração do caráter contraditório das sociedades moldadas segundo o parâmetro fundamental do modo de produção capitalista (Rachi, 1990). Nesse sentido, as possibilidades de ação do profissional de psicologia rumo a práticas diferenciadas também devem ser colocadas no contexto do papel do intelectual numa sociedade contraditória(Gramsci, 1979; Lukács, 1923/1974; Pécaut, 1990; Yamamoto, 1996a). É na confluência desses dois vetores que se pode discutir, de forma mais substantiva, possíveis (re)direcionamentos do exercício e, como condição preliminar, da formação acadêmica dos psicólogos.

\section{Agradecimentos}

A execução deste projeto contou com o apoio institucional do CNPq (bolsa para O. H. Y., processo n ${ }^{\circ}$ 520218/96-5; bol- 
sas PIBIC para G.S.S. e S.C.C.O.) e da PPPg-UFRN. Os autores agradecem a colaboração de Nadja Marques Guerra, Janaísa Leão Antunes de Lima, Margareth Rose Barreto de Lima, Jaíra Furtunato Maia, Francineide Nogueira Mendonça e Sisméria Cruz de Souza pelo trabalho de coleta, organização e discussão dos dados do projeto; ao prof. Herculano R. Campos, pelas observações acerca de uma versão preliminar deste trabalho; e ao Conselho Regional de Psicologia, $2^{\text {a }}$ Região, pelas informações prestadas.

\begin{abstract}
The Psychology in Rio Grande do Norte: general data on academic background and professional activity. The purpose of this work was to outline the status of Psychology in the state of Rio Grande do Norte, including the academic background and the professional activity of psychologists. A standard questionnaire was sent to each of the 448 psychologists living in the state and inscribed at the Conselho Regional de Psicologia (Regional Council of Psychology), 2nd Region. The final sample was 190 psychologists $(42,4 \%)$. Among the results - confirming national and local data (Conselho Federal de Psicologia, 1988; Yamamoto, 1988) - are the prevalence of Health Psychology as the main area $(67,5 \%)$, followed by Work $(14,4 \%)$, Educational $(10,1 \%)$ and others. In respect to gender, $88,4 \%$ of psychologists are females. Whereas this study is just an overview - part of a wider research project about the professional activities of psychologist in RN, some implications of these results are discussed.

Key words: Psychology in Brazil, Psychology in Rio Grande do Norte, Psychology as a profession, Psychologist's academic background.
\end{abstract}

\title{
Referências
}

Antunes, R. (1995). Adeus ao trabalho? Ensaios sobre as metamorfoses e a centralidade do mundo do trabalho ( $2^{\mathrm{a}}$ ed.). São Paulo: Cortez. 
Bastos, A. V. B. (1988). Áreas de atuação: Em questão o nosso modelo de profissional. In Conselho Federal de Psicologia (Org.), Quem é o psicólogo brasileiro? (pp. 163-193). São Paulo: Edicon.

Bastos, A. V. B. (1990). Mercado de trabalho: Uma velha questão e novos dados. Psicologia: Ciência e Profissão, 2/3/4, 28-39.

Bastos, A. V. B. \& Achcar, R. (1994). Dinâmica profissional e formação do psicólogo: Uma perspectiva de integração. In Conselho Federal de Psicologia (Org.), Psicólogo brasileiro: Práticas emergentes e desafios para a formação (pp. 245-271). São Paulo: Casa do Psicólogo.

Campos, R. H. F. (1983). A função social do psicólogo. Educação \& Sociedade, 16, 74-84.

Carvalho, A. M. A. (1988). Atuação psicológica: Uma análise das atividades desempenhadas pelos psicólogos. In Conselho Federal de Psicologia (Org.), Quem é o psicólogo brasileiro? (pp. 217-235). São Paulo: Edicon.

Carvalho, A. A., Ulian, A. L. A. O., Bastos, A. V. B., Sodré, L. G. P., \& Cavalcante, M. L. P. (1988). A escolha da profissão: Alguns valores implícitos nos motivos apontados pelos psicólogos. In Conselho $\mathrm{Fe}-$ deral de Psicologia (Org.), Quem é o psicólogo brasileiro? (pp. 49-68). São Paulo: Edicon.

Conselho Federal de Psicologia (Org.). (1988). Quem é o psicólogo brasileiro? São Paulo: Edicon

Conselho Federal de Psicologia (Org.). (1992). Psicólogo brasileiro: Construção de novos espaços. Campinas: Átomo.

Conselho Federal de Psicologia (Org.). (1994). Psicólogo brasileiro: Práticas emergentes e desafios para a formação. São Paulo: Casa do Psicólogo.

Conselho Regional de Psicologia - 6 a Região (1995). Psicologia: Formação, atuação profissional e mercado de trabalho (Estatísticas 1995). São Paulo: Autor.

Duran, A. P. (1994). Alguns dilemas na formação do psicólogo: Buscando sugestões para superá-los. In Conselho Federal de Psicologia (Org.), Psicólogo brasileiro: Práticas emergentes e desafios para a formação (pp. 273-310). São Paulo: Casa do Psicólogo.

Figueiredo, M. A. C. (1989). O trabalho alienado e o psicólogo do trabalho: Algumas questões sobre o papel do psicólogo no controle da produção capitalista. São Paulo: Edicon.

Francisco, A. L., \& Bastos, A. V. B. (1992). Conhecimento, formação e prática. In Conselho Federal de Psicologia (Org.), Psicólogo brasileiro - construção de novos espaços (pp. 211-227). Campinas: Átomo.

Frigotto, G. (1995). Educação e a crise do capitalismo real. São Paulo: Cortez. 
Gomide, P. I. C. (1988). A formação acadêmica: onde residem suas deficiências? In Conselho Federal de Psicologia (Org.), Quem é o psicólogo brasileiro? (pp. 69-85). São Paulo: Edicon.

Gramsci, A. (1979). Os Intelectuais e a organização da cultura. (3a . ed.). Rio de Janeiro: Civilização Brasileira.

Instituto Brasileiro de Geografia e Estatística (s. d.). Pesquisa nacional por amostras de domicílios - PNAD 1993, Rio Grande do Norte. Manuscrito não-publicado.

Japiassu, H. (1979). A psicologia dos psicólogos. Rio de Janeiro: Imago.

Lukács, G. (1974). História e consciência de classe. Porto: Escorpião. (Obra original publicada em 1923)

Mello, S. L. (1975a). Psicologia e profissão em São Paulo. São Paulo: Ática.

Mello, S. L. (1975b). A formação profissional dos psicólogos: Apontamentos para um estudo. Psicologia, 1, 15-20.

Patto, M. H. S. (1984). Psicologia e ideologia. São Paulo: T.A. Queiróz.

Pécaut, D. (1990). Os intelectuais e a política no Brasil: Entre o povo e a nação. São Paulo: Ática.

Pessotti, I. (1988). Notas para uma história da psicologia brasileira. In Conselho Federal de Psicologia (Org.), Quem é o psicólogo brasileiro? (pp. 17-31). São Paulo: Edicon.

Rachi, K. (1990). Educação escolar brasileira: Um reexame dos estudos tendo por centro de análise a categoria de "contradição". Dissertação de Mestrado. São Paulo: Pontifícia Universidade Católica de São Paulo.

Rosas, P., Rosas, A., \& Xavier, I. B. (1988). Quantos e quem somos. In Conselho Federal de Psicologia. (Org.), Quem é o psicólogo brasileiro? (pp. 32-48). São Paulo: Edicon.

Rosemberg, F. (1984). Afinal, por que somos tantas psicólogas? Psicologia, Ciência e Profissão. 1, 6-12.

Sader, E., \& Gentili, P. (Orgs.) (1995). Pós-neoliberalismo: As políticas sociais e o estado democrático. Rio de Janeiro: Paz e Terra.

Sindicato dos Psicólogos no Estado de São Paulo/Conselho Regional de Psicologia-6 ${ }^{\text {a }}$. Região. (1984). O perfil do psicólogo no Estado de São Paulo. São Paulo: Cortez.

Witter, G. P., Gonçalves, C. L. C., Witter, C., Yukimitsu, M. T. C. P., \& Napolitano, J. R. (1992). Formação e estágio acadêmico em psicologia no Brasil. In Conselho Federal de Psicologia (Org.), Psicólogo brasileiro construção de novos espaços (pp. 181-209). Campinas: Átomo.

Yamamoto, O. H. (1987). A crise e as alternativas da psicologia. São Paulo: Edicon. 
Yamamoto, O. H. (1988). Apontamentos para um estudo da psicologia em Natal: Áreas de atuação e seus determinantes. Revista de Psicologia, 1,3-13.

Yamamoto, O. H. (1996a). Educação e a tradição marxista: A produção educacional marxista no Brasil dos anos 70/80. São Paulo/Natal: Moraes/Editora Universitária UFRN.

Yamamoto, O. H. (1996b). Neoliberalismo e políticas sociais: O impacto na Psicologia brasileira. Psicologia Revista, 2, 12-26.

Yamamoto, O. H., Souza, I. M. S., Oliveira, I. A., Silva, L. N. M., Freire, M. A. A., Rocha, R. M., \& Alves, Filho, S. (1990). A psicologia escolar em Natal: Características e perspectivas. Psicologia: Ciência e Profissão, $2 / 3 / 4,40-49$.

Yamamoto, O. H., Spinelli, S. M., \& Carvalho, D. B. (1996). O psicólogo escolar em Natal: em busca de uma identidade profissional. Psicologia: Reflexão e Crítica, 2, 13-26.

\section{Notas}

${ }^{1}$ Para considerações acerca da questão, ver Pessotti (1988).

${ }^{2}$ Na ocasião em que a listagem foi obtida, a Décima-terceira Região do Conselho Regional de Psicologia - desmembramento do Segunda Região, abarcando os estados do Rio Grande do Norte e da Paraíba - estava sendo constituída. No entanto, os dados do recadastramento dos psicólogos do estado do RN ainda não estavam disponíveis.

${ }^{3}$ Um dado que chama a atenção no caso local é o fato de Psicologia ter sido o curso mais concorrido dentre os 40 oferecidos pela universidade, com uma relação de mais de 25 candidatos por vaga. Evidentemente, existem algumas condições específicas envolvidas - como o próprio número absoluto de vagas -, mas não deixa de ser um dado surpreendente a procura pelo curso de Psicologia ter suplantado os cursos mais tradicionalmente atraentes, como as Engenharias, Medicina, Direito e aqueles do campo das Comunicações.

${ }^{4}$ De fato, se tomarmos apenas os profissionais que não obtiveram seu grau na UFRN, a maior frequiência localiza-se na faixa etária de 41-45 anos (39,5\%); 88,8\% dos psicólogos situam-se na faixa superior a 36 anos. Inversamente, dentre aqueles formados pela UFRN, 68,5\% situamse na faixa inferior a 35 anos, demonstrando nitidamente o contraste.

${ }^{5}$ Os dados que estamos analisando dizem respeito aos alunos formados até o ano de 1995. Nesse momento, o Curso de Psicologia já havia pas- 
sado por uma reforma curricular na qual estágios de curta duração são ofertados antes do estágio curricular obrigatório, que continua a ser objeto de opção.

${ }^{6}$ Se computarmos, dentre os profissionais que exercem atividade em psicologia, os que têm uma segunda atividade, sendo ou não vinculada à psicologia, o percentual aumentará para 58,5\%.

7 Para análises das questões envolvidas na formação de psicólogos, ver, entre outros, Mello, 1975b; Gomide, 1988; Francisco \& Bastos, 1992; Witter et al., 1992; Bastos \& Achcar, 1994 e Duran, 1994).

Oswaldo H. Yamamoto é professor do Departamento de Psicologia, do Programa de Pós-Graduação em Educação da Universidade Federal do Rio Grande do Norte e Coordenador do Grupo de Pesquisa Marxismo \& Educação (Diretório de Grupos de Pesquisa do Brasil/CNPq). Doutor em Educação pela Universidade de São Paulo (SP). Endereço para correspondência: Universidade Federal do Rio Grande do Norte, Departamento de Psicologia, Caixa Postal 1622, Campus Universitário, CEP 59.078-970, Natal, RN,e-mail: yamamoto@cchla.ufrn.br. Gilmara da S. Siqueira $e$ Samantha C. da Costa Oliveira são estudantes do curso de Psicologia da UFRN e bolsistas de iniciação cientifica, programa PIBIC/CNPq/UFRN. 